\title{
0 "Grande Irmão" e a empresa: indústria cultural, reality shows e espetáculos organizacionais
}

\author{
Marcos Goulart Castelo* \\ José Luis Felício dos Santos de Carvalho**
}

\begin{abstract}
Resumo
A motivação para este ensaio relaciona-se à busca de uma via mais direta de comunicação entre pesquisadores descontentes e participantes organizacionais pouco identificados com leituras críticas e mais interessados em render homenagem a certos produtos da indústria cultural. 0 objetivo do texto é revelar pontos de tangência entre programas de reality show e organizações produtivas, movimento para o qual se convida outros acadêmicos igualmente inconformados com a recorrente dificuldade de estabelecer um diálogo crítico entre teóricos e praticantes. Inicialmente, o texto discute cultura de massa, reality shows e empresas como produtos e produtores de uma representação social focada no espetáculo e na hiper-realidade, para depois ilustrar sua argumentação por meio do desenvolvimento de três facetas do problema: seleção de participantes, jogos de poder e manipulação de comportamentos. Nesse contexto, a posição de acadêmicos como meros espectadores não parece condizente com os desafios enfrentados pelos jogadores/participantes/atores dos programas e das organizações.
\end{abstract}

Palavras-chave. : 'reality show', indústria cultural, hiperrealidade, sociedade do espetáculo, teoria crítica

\begin{abstract}
This essay aims a closer communication between dissatisfied researchers and organizationals actors not so effectively identified with critical readings and more interested in paying homage to certain products of the cultural industry. The main goal of the text is to disclose the closing points between reality shows and productive organizations. In this sense it invites other equally unsatisfied academics with the recurrent difficulty to establish a critical dialogue between theoreticians and practitioners. Initially the text discusses mass culture, reality shows and companies as products and producers of a social representation focused on the show and the hiperreality. It illustrates its arguments presenting three aspects of the problem: selection of participants, power saggy games and behavior manipulation. In such context, the position of academics as mere spectators does not seem to accord with the challenges faced by the players/participants/actors of the programs and the organizations.
\end{abstract}

keywords: reality show, cultural industry, hyperreality, spectacle society, critical theory

\section{Introdução}

Ao longo da última década, os reality shows tornaram-se os maiores campeões de audiência e vendas de espaço publicitário da história da mídia televisiva, bem como poderosos determinantes de modificação comportamental (JONES, 2003; MATHIJS, 2002). Por outro lado, esses programas também foram alvo de críticas ferozes, notadamente nos campos da sociologia, da comunicação e da psicologia (CORREIA, 2003). Surpreendentemente, apesar dos incontáveis pontos de tangência entre reality shows e administração de empresas, os estudiosos das organizações parecem ter preferido ficar à margem de tais discussões.

Neste estudo, pretende-se endossar de pronto a assertiva de que muito pode ser ganho ao se observar criticamente os reality shows, não como eventos bizarros ou experimentos desumanos, mas como produtos de uma estrutura social definida (MATHIJS, 2002) que confia nas organizações produtivas para obter

Professor adjunto da Faculdade de Administração e Ciências Contábeis da Universidade Federal do Rio de Janeiro (FACC/UFRJ). E-mail:marcos.castelo@ uol.com.br.

Professor adjunto da Faculdade de Administração e Ciências Contábeis da Universidade Federal do Rio de Janeiro (FACC/UFRJ). E-mail: zkcarvalho@ hotmail.com.

Artigo recebido em julho de 2004 e aceito em setembro de 2004. 
desenvolvimento econômico (INGHAM, 1993), e que precisa criar dispositivos capazes de reforçar a dominação ideológica e atenuar as contradições do sistema (BASTIDE, 1971; LUKÁCS, 1989). Se empresas e reality shows podem ser vistos como reflexos geminados de uma mesma estrutura socioeconômica, é provável que o exame de seus contrastes e semelhanças possa auxiliar no entendimento do fenômeno organizacional.

Confiando na idéia de que a ampliação do entendimento do mundo das organizações, em virtude de sua complexidade, demanda investigar outros objetos que não as próprias empresas (WEICK, 2002), é proposto aqui que este artigo esteja orientado para o objetivo primário de examinar pontos de contato entre reality shows e empresas produtivas, com a finalidade de aprofundar a compreensão acerca destas. Como propósito secundário, é sugerido que este estudo possibilite que os reality shows - assim como outros produtos emblemáticos da indústria cultural - inspirem novos caminhos de pesquisa para acadêmicos de administração.

Empresas e reality shows parecem guardar interseções notáveis. Seria exagero admitir que tanto no programa Big Brother quanto na maioria das empresas habitam indivíduos entregues a comportamentos forjados, intrigas, disputas por status, manipulação, coalizões por interesse? E com relação àqueles que dirigem os espetáculos na televisão e na organização, seria absurdo se falar em seleção de participantes com base em estereótipos, jogos de poder, regras, vigilância e outras formas de controle do comportamento?

Para responder a essas e a outras questões, optou-se não por seguir a via óbvia porém problemática da metáfora (McALLISTER, 1998), mas pela construção de uma analogia (PERELMAN e OLBRECHTS-TYTECA, 1996), possibilidade epistemológica que tem seu valor argumentativo atrelado à confrontação de uma similaridade de estruturas entre um tema pretendido (neste caso, a organização) e um foro analógico (o reality show).

O artigo está divido em sete seções, incluindo esta introdução. Na segunda, é elaborado um retrato dos reality shows como produtos da indústria cultural amparada na via midiática, para reforçar o projeto de controle social por parte da classe dominante. A terceira seção extrapola a questão da cultura de massa para as teorias de espetacularização da sociedade e construção de hiper-realidade. A quarta seção inicia a analogia pretendida, por meio de considerações quanto ao processo seletivo nas empresas e nos programas de reality show. Na quinta, são discutidos os jogos de poder e as estratégias empreendidas por jogadores-atores e jogadores-funcionários para realizar seus objetivos. Na sexta parte, é debatida a manipulação das pessoas pela classe dominante, esteja ela representada pelos produtores, nos programas de reality show, ou pela alta administração, nas organizações. Na última seção, são apresentadas as conclusões, as quais incluem sugestões para uma agenda de pesquisa.

\section{Reality shows : contextualização, ideologia e características}

Ainda que muitos estudiosos de organizações pareçam reconhecer que a observação das manifestações artísticas e culturais resulte em possíveis e consideráveis benefícios para o entendimento do mundo empresarial e o desenvolvimento da ação organizacional (CARR, 2002; WEICK, 2002), pouca atenção se tem dado à indústria cultural para esse tipo de estudo. Isso talvez decorra de sua relação direta e imediata com os mecanismos de dominação ideológica (ADORNO e HORKHEIMER, 1997), os quais podem encaminhar a discussão para os nem sempre familiares territórios da estética ou da semiótica.

A crítica à indústria cultural pode propiciar uma base de reflexões para uma investigação mais vigilante do fenômeno organizacional, e fomentar construções teóricas relevantes, uma vez que empresas e cultura de massa são produtos de um mesmo projeto histórico de controle social e de apropriação de diversos aspectos da realidade, por parte de determinados interesses econômicos (COOPER e BURRELL, 1988; FRIDMAN, 2000).

Estranhamente, mesmo quando são considerados os fenômenos da mídia de massa, ainda que se esteja pesquisando inquestionáveis sucessos de mercado, como os reality shows, raros têm sido os estudos em administração preocupados com a questão, salvo minguadas exceções, como, por exemplo, Mixon Jr.(2001) e Taylor (2000), as quais normalmente são desenvolvidas em resposta a uma demanda instrumental, não decorrentes de reflexão crítica. 
No Brasil, país apontado como naturalmente afeito à espetacularização (BELK, 1996) e à mitologização midiática (TAVARES, 2000), os acadêmicos parecem não ter despertado para o tema, talvez em função de certo desprezo por sua aparente simplicidade. Por outro lado, deve-se atentar para o fato de que aqui o Big Brother assumiu características peculiares (XEXÉO, 2004), pois em nenhum outro país, obtiveram sucesso quatro edições do programa, que se transformou em gerador incomparável de receitas para as empresas detentoras das cotas de merchandising e espaço publicitário. Desnecessário mencionar que mesmo que somente a faceta comercial do problema estivesse em pauta, não se deseja crer que os temas do reality show e da cultura de massa possam ser marginalizados por pesquisadores de administração.

A indústria cultural é fundamental para o funcionamento do sistema capitalista, principalmente, em decorrência de sua essência narcisista. Para impulsionar relações de oferta e demanda, ela vende aos consumidores "a satisfação manipulada de se sentirem representados nas telas do cinema e da televisão" (FREITAS, 2003, p.19): seus heróis são elaborados para refletirem algo que os espectadores já percebem em si próprios; porém, essa semelhança é potencializada pela elaboração técnica. Nos reality shows, essas diretivas são levadas ao limite pelo artifício da transposição de indivíduos até então desconhecidos do público para situações nas quais eles passam a ter suas vidas acompanhadas por milhões de pessoas. Configura-se, portanto, a díade exibicionismovoyeurismo, responsável pela transformação de relações mercadológicas entre empresas (canais de televisão e anunciantes) e clientes (a audiência) numa experiência de hedonismo e fantasia (HOLBROOK, 2001).

A faceta narcisista dos reality shows desemboca, destarte, no entretenimento dos espectadores por meio de uma competição acirrada, travestida num jogo em que se empreende uma perseguição legitimada pelos prêmios de fama instântanea, sucesso rápido e/ou dinheiro fácil (CORREIA, 2003). A indústria cultural funciona, assim, como um mito de felicidade a ser alcançada, mas conseguida somente de forma ilusória (FRÉMION, 2000), na expectativa frustrada da realização pessoal sem esforço e no consumo desenfreado (FREITAS, 2003).

Fenômenos de audiência derivados da complexidade midiática característica da virada do milênio (CORREIA, 2003; TINCKNELL e RAGHURAM, 2002), os reality shows podem ser retratados como híbridos entre documentário, jogo e novela, posicionando-se no negócio do entretenimento de suas audiências por meio da explicitação de questões como identidade, representação, prazer e interatividade (JONES, 2003; MATHIJS, 2002).

É possível considerar que o reality show nasceu com a estréia de Road Rules, exibido pela MTV norteamericana desde 1997. É um programa-gincana, no qual um grupo de jovens viaja em caravana, de uma cidade a outra, cumprindo determinados desafios (ANDREJEVIC, 2002). No ano 2000, o programa Big Brother lançado no ano anterior na Holanda - obteve repercussão sem precedentes nos EUA, na Inglaterra e em muitos outros países da Europa, proporcionando enorme retorno para anunciantes e patrocinadores (TINCKNELL e RAGHURAM, 2002).

Com seu nome emprestado da obra 1984, de George Orwell (1978), mas não inspirado numa intrusão governamental de cunho totalitarista e sim no reflexo da participação da mídia e de empresas produtivas em absolutamente todas as instâncias da vivência (ANDREJEVIC, 2002), Big Brother mostra a rotina de pessoas comuns confinadas em uma casa, com o mote de se poder acompanhar trechos supostamente autênticos da vida real de pessoas nas quais os espectadores não teriam dificuldades em se espelhar (MATHIJS, 2002).

Outros modelos estrangeiros e brasileiros de reality show buscaram reproduzir o estrondoso sucesso de Big Brother, quase todos com excelente desempenho: alguns programas mostram pretendentes a artistas em busca de reconhecimento na televisão (Protagonistas de Novela) ou na música (American Idol, Fama, Pop Stars); outros apresentam pessoas à procura de relacionamentos ideais, em disputa com outros pretendentes (Joe Millionaire, The Bachelor) ou pela transformação de suas personas (Queer Eye For The Straight Guy); outros ainda contemplam indivíduos em busca da superação de seus limites físicos (No Limite, Survivor) ou aventureiros em viagens extremas ( $O$ Conquistador do Fim do Mundo). Existe até mesmo um reality show ambientado no mundo dos negócios, cujo prêmio é um emprego em uma grande corporação (The Apprentice). 
Por mais distintos que sejam os formatos dos reality shows, foram detectados alguns pontos comuns que, tomados em seu conjunto, caracterizam o gênero (ANDREJEVIC, 2002; JONES, 2003; SCANNELL, 2002). O quadro 1 relaciona as principais características dos reality shows, quase todas presentes na maioria dos programas do gênero, veiculados no Brasil e em outros países.

\section{Quadro 1}

Características dos reality shows

- seleção criteriosa dos participantes - privilegia-se os jogadores aptos a disseminar os valores e a propagar a imagem requerida pelos autores ou diretores do programa

- hipercompetitividade - os participantes competem entre si, contra os donos do jogo e/ou contra os espectadores interativos

- sistemas de punição e recompensa - condutas desejáveis são premiadas ou reforçadas, enquanto os comportamentos desviantes são penalizados ou repreendidos

- impressão de brincadeira - por mais que alguns jogadores estejam disputando prêmios valiosos, subsiste uma atmosfera ludica ou aparentemente despreocupada

- vigilância constante - acompanhamento ininterrupto de câmeras e microfones, mesmo nas situações em que a intimidade poderia ser desejada pelos jogadores

- interferência controlada do mundo externo - os participantes têm acesso restrito às informações e aos estímulos vindos do exterior

- formação de coalizões de poder - jogadores com afinidades estabelecem alianças para satisfazer objetivos comuns ou quando o jogo pede trabalho em equipe

- isolamento dos participantes - impedimentos ao contato com familiares e amigos durante o programa restringem as relações de um jogador aos demais participantes

- confinamento no espaço - os jogadores são colocados em ambientes delimitados, tais como uma casa, uma clareira na floresta ou uma academia de ginástica

- codificação de ações e falas - vocabulários e atitudes adotadas pelos preferidos do público em um programa são apropriados e reproduzidos nos programas seguintes

- normatização - autores e diretores estabelecem normas de convivência e participação, sem as quais não se permite que um jogador continue no programa

- manipulação do comportamento - permamente tentativa de influenciar e comandar ações e discursos de umjogador por autor, diretor e demais jogadores

- interatividade - os espectadores participam ativamente da produção do programa e podem modificar seu desenvolvimento.

Fonte: os autores

Não é preciso realizar grandes malabarismos intelectuais para que, num exame rápido do quadro 1, sejam percebidas diversas similaridades entre um reality show e uma empresa, muitas das quais poderiam ser desdobradas em subtemas a serem explorados mais detidamente. No entanto, em virtude da limitação de espaço, este artigo tratará sucintamente de apenas três desses tópicos - da "seleção criteriosa dos participantes", da "formação das coalizões de poder" e da "manipulação do comportamento" -, a título de ilustração, como se verá a partir da quarta seção.

Além disso, cabe acrescentar que o estrondoso sucesso de público obtido pelos reality shows motivou o grupo norte-americano Fox Networks Group a anunciar, em julho de 2004, a intenção da empresa em lançar um canal de televisão exclusivo para os admiradores do gênero (TELEVISÃO, 2004). Apesar de algumas projeções indicarem certo risco de saturação quanto a esse tipo de programa, o domínio de audiência conseguido por The Swan (um reality show que transformou um patinho feio em Cinderela por meio de cirurgias plásticas) 
contribuiu para que a emissora estabelecesse planos para no início de 2005 promover o lançamento do Fox Reality Channel.

\section{Espetáculos de realidade e hiper-realidade}

Paradoxalmente, os supostos shows de realidade oferecidos pelos canais midiáticos pouco guardam em comum com a vida real. Como característica principal - inerente às peculiaridades da comunicação televisiva (PALLOTTINI, 1998) -, não ocorre uma procura estética pela verossimilhança e pela realidade, mas a busca por uma simulação idealizada da vida (BAUDRILLARD, 1990). O princípio da simulação não reside na idéia de que aquilo que é real na verdade é falso, mas na percepção de que uma distinção efetiva entre real e falso é impossível. Quando ocorre tal distorção entre a vida real e aquilo que é imaginário ou fictício, cria-se uma nova experiência, a da hiper-realidade (SMITH, 2002).

A hiper-realidade é uma versão desinfetada da realidade, higienizada dos problemas mundanos, da sujeira, da violência, da exploração e das demais dificuldades impostas pelo cotidiano (BELK, 1996). A partir do momento em que não existe uma insistência para se enfatizar aquilo que é real, não se pode falar da verdade, somente de uma representação, a qual pode ser extrapolada para a realidade. Trata-se da construção de uma nova verdade a partir de uma hiper-realidade (SMITH, 2002), por meio da qual tende-se a privilegiar a fantasia, a estilização e o espetáculo (DEBORD, 1995), de acordo com a concepção de que as sociedades atuais não passam de produções cinematográficas e dramatúrgicas (PELZER, 2002; WOOD JR., 2000).

Por meio da dominância dos aspectos hiper-reais do cotidiano, abre-se espaço para a banalização da vida (DEBORD, 1995) - principalmente, em função da hegemonia dos canais midiáticos de comunicação -, a qual contribui para a dominação ideológica (ADORNO, 1990; BASTIDE, 1971; HAUSER, 1966), ao embotar a capacidade crítica dos indivíduos e atrofiar a imaginação e a espontaneidade do consumidor da cultura de massa (ADORNO e HORKHEIMER, 1997; KOZINETS, 2002). O televisionamento da realidade desempenha um papel particularmente importante no treinamento de espectadores e consumidores para a assunção de seus papéis numa economia de mercado baseada na interatividade (ANDREJEVIC, 2002).

Os produtos da indústria cultural não permitem a atividade intelectual do espectador, se ele não quiser perder as imagens e os pseudo-eventos que desfilam diante de seus olhos (ADORNO e HORKHEIMER, 1997). O espetáculo, inspirado na semiótica hollywoodiana, seqüestra a vida, pois a adesão à ordem espetacular é consolidada por meio de um fluxo ininterrupto de imagens e fantasias (BAUDRILLARD, 1990) que substitui a vivência (FRIDMAN, 2000).

Podemos tomar como exemplo Gran Hermano, a versão colombiana do Big Brother (VAN DONGEN, 2003). Em um país abalado por guerra civil, violência urbana e conflitos políticos, os participantes do reality show que apresentavam comportamento mais explosivo eram prontamente eliminados pelos espectadores, que decidiam pela permanência ou pela saída de determinado jogador. Para sagrar-se vencedor, o participante do programa deveria, em primeiro lugar, viver em paz e harmonia com os demais jogadores, ou seja, o preferido do público seria aquele jogador que apresentasse um comportamento oposto àquele que os colombianos eram forçados a vivenciar em seu cotidiano. No programa Protagonistas de Novela, foram excluídos todos os jogadores considerados oportunistas e manipuladores pela platéia; curiosamente, tais características eram percebidas (e lamentadas) pelos colombianos como os traços de personalidade predominantes em grande parcela de seu próprio povo.

Assim, a emergência dos reality shows como inigualáveis fenômenos de mídia ao final do século XX (TINCKNELL e RAGHURAM, 2002) pode ser percebida como um distanciamento ainda maior entre real e hiper-real, principalmente, por conta da simulação embutida na venda de tais programas como pedaços autênticos de realidade. Por meio da mídia, então, pode-se elaborar um mundo saneado em que a paz, a harmonia e a beleza plástica e asséptica provêm a única fonte crível de gratificação estética (DALE e BURRELL, 2002; HANCOCK, 2002). 
Transmissões ao vivo e câmeras disponíveis na internet permitem acompanhar os jogos de reality show no exato momento em que acontecem os principais lances da competição (SCANNELL, 2002), proporcionando o "fascínio da simultaneidade" (HAUSER, 1966, p.54), artifício fundamental para se chegar à "epifania do eterno presente", traduzida na colonização do inconsciente requerida pelos ditames da indústria cultural (ALVESSON e DEETZ, 1999; FRIDMAN, 2000).

A idealização da realidade é um requisito determinante para o sucesso do projeto modernista de desenvolvimento e controle social por meio da razão (BELL e TAYLOR, 2004; COOPER e BURRELL, 1988) e, por conseguinte, ela é essencial para a atividade organizacional (ENRIQUEZ, 2001). Nas empresas, a idealização representa o meio mais comum de se conter impulsos agressivos, constituindo um esforço para "impedir que uma 'boa' imagem não seja contaminada por uma "má' imagem" (DE VRIES, 1996, p.77). Através desse mecanismo, sentimentos, experiências e percepções tidos como "bons" ou "maus" são polarizados, com o intuito de impedir a construção de uma realidade povoada de intenções ambíguas ou contaminadas.

Os exemplos clássicos da perspectiva hiper-real aplicada ao mundo das organizações são representados pela Disney e pelo McDonald's (BOJE, 2002), conquanto se possa dizer que quando uma empresa qualquer enfatiza a simulação e o espetáculo, constitui-se uma ocasião favorável para a construção de uma hiper-realidade (BELK, 1996).

Criar - para público interno e externo, ou melhor, para participantes e espectadores - uma realidade mais perfeita do que aquela propiciada pela experiência vivencial, assim é que se dá nome ao jogo. Disney, Big Brother e muitos outros empreendimentos e empresas dedicam-se incessantemente a criar um espetáculo hiperreal relacionado à evolução e à transformação, sustentado pela imagética da mudança e da renovação, com o propósito bem definido de manter adormecidas as forças capazes de causar abalos ou fissuras na realidade. Nas próximas seções, os autores deste texto ensaiam descortinar alguns dos mecanismos pelos quais organizações e canais de televisão buscam atingir esse objetivo.

\section{Processo seletivo de jogadores e funcionários}

Para que as empresas transformem indivíduos recém-chegados em "homens da organização" (ENRIQUEZ, 1997, p.51), é preciso que essas pessoas passem a agir e se comunicar "todas da mesma maneira", dediquem-se plenamente às suas tarefas e se "comportem como 'heróis', 'guerreiros' e 'esportistas"”. Às empresas, interessa sobremaneira as competências individuais e características pessoais que podem ser encontradas nas imagens do guerreiro vencedor (SARSUR e SILVA, 2002) ou do herói de ficção (TONELLI e ALCADIPANI, 2000). Não por acaso, estas parecem ser exatamente as mesmas atribuições que se espera de um participante do programa Big Brother (SANTOS, 2004).

A escolha dos participantes constitui uma das etapas mais importantes para o sucesso dos reality shows (MURPHY, 2003). É por meio de uma boa seleção de candidatos que os dramas, conflitos, casos amorosos, complôs e diversas outras situações criadoras de audiência podem ser estimulados. De acordo com a concepção aristotélica da catarse (FISCHER, 1966; PINHEIRO, 2000) - igualmente fundamental para a cultura de massa (MARCONDES FILHO, 1986) - os realizadores de reality shows não necessitam de indivíduos questionadores, amantes dos livros e capazes de reflexões elaboradas. Devem ser escolhidos jogadores capazes de namorar muito, conversar com o espelho, falar sobre moda e, principalmente, meter-se em discussões vãs e brigas por motivos banais (SANTOS, 2004).

Isso implica que determinado perfil de candidato deva ser selecionado. Esse perfil irá variar de acordo com o tipo de reality show; mas percebe-se que há uma preocupação em escolher representantes de todas as classes sociais e etnias, pessoas de áreas urbanas e rurais, jovens e adultos de meia idade, muitas pessoas belas e algumas feias, criando uma variedade de tipos e "personagens" que visa estimular a ocorrência de conflitos e permitir que todos os segmentos da população tenham com quem se identificar. Na psicologia da indústria 
cultural, os espectadores precisam purgar seus medos e ansiedades por meio da identificação com aqueles que estão em cena (FISCHER, 1966; MARCONDES FILHO, 1986).

É interessante perceber como nos reality shows e nas empresas são seguidos os mesmos preceitos de exclusão e inclusão relacionados às minorias. Tomando como exemplo a questão das relações de raça, verifica-se a predominância nos cenários da organização e do Big Brother da noção de "brancura como critério de estética social" (GUERREIRO RAMOS, 1995, p.216). No reality show, acredita-se que as platéias prefiram conhecer a intimidade de jogadores brancos; no entanto, é "politicamente correto" incluir participantes da raça negra. Assim, em todas as edições brasileiras do Big Brother é convocado um casal de negros. Geralmente, são escolhidos por sua adequação ao estereótipo: o homem é sempre brincalhão, sedutor e amante da cerveja e do pagode; enquanto a mulher tem os traços finos e adora sambar para as câmeras. Nas organizações produtivas, de acordo com as recentes demandas da cidadania corporativa, verifica-se a inclusão de funcionários negros não por serem mais capacitados, mas pelo simples fato de serem negros. Segue-se, portanto, a perspectiva da responsabilidade social para cumprir a função de melhoria da imagem corporativa, não como fundamento substancial da ação organizacional (MENDONÇA e GONÇALVES, 2002).

Se, nos reality shows, a seleção de pessoas por estereótipos visa satisfazer à identificação do público e gerar picos de audiência, mais importante ainda torna-se analisar cuidadosamente a personalidade dos jogadores, procurando prever quais possíveis combinações de tipos humanos poderão interessar mais ao público. Pode-se considerar que em empresas acontecem mecanismos similares. Também existe um perfil ideal de candidato, o qual precisa ser versátil e determinado, saber se comunicar (ZARIFIAN, 2001), conseguir trabalhar em equipe e manifestar habilidade para liderar (SILVA, 2000; WEINBERG e BRASIL, 2003).

Esse perfil ideal de profissional que as empresas esperam parece estar mais ligado à personalidade do candidato do que aos conhecimentos formais que ele adquiriu ao longo da vida (CHIARI, 2000). Dessa observação depreende-se que o caráter subjetivo das características que indicam um bom profissional mostra que a atitude é de extrema importância para um bom desempenho e, ao mesmo tempo, dá maior margem para a simulação nos processos seletivos. Apesar dos profissionais de recrutamento recomendarem que candidatos a vagas em organizações não procurem aparentar aquilo que não são (GALVÃO, 2000), ou seja, que não busquem forjar um comportamento para enganar os avaliadores, existem incontáveis cursos e livros que ensinam aos candidatos a representar o papel de um candidato ideal, como se vestir e se comportar nas dinâmicas e entrevistas (CARVALHO e GRISCI, 2002).

Dessa maneira, os processos de seleção tornam-se ocasiões em que predomina a interpretação dramática, por meio da qual se avalia, principalmente, a capacidade do candidato de representar o papel proposto pelos profissionais de recursos humanos (CARVALHO e GRISCI, 2003; NOGUEIRA, 2002). Tanto a dinâmica quanto o processo seletivo tornaram-se jogos de aparências: o currículo deve ter uma boa aparência, e na dinâmica e entrevista o candidato deve destacar sua aparência por meio da fala e da postura, devendo atuar como um showman ou uma showoman (CASE, 2004).

Nascem assim os empregados que se tornam personalidades, cuja maior competência é vender a si próprios. Eles conquistam os profissionais de recrutamento e seleção com um comportamento que demonstra potencial, mas posteriormente, no cotidiano de trabalho, escoram-se numa postura manipuladora (MAcCOBY, 2000), à guisa das celebridades criadas pelos reality shows que depois caem no esquecimento por não terem valor artístico algum, a não ser exibir-se incessantemente para as cansadas lentes dos fotógrafos.

Muitas vezes, a seleção com base em estereótipos acontece de forma inconsciente nas organizações, no chamado "preconceito implícito" ou favorecimento do grupo (BENAJI, BAZERMAM e CHUGH, 2003). Ao avaliar que o candidato possui determinadas características condizentes com o perfil ideal ou ao aferir que o candidato tem referências socioculturais semelhantes às suas, o recrutador automaticamente cria uma boa imagem dessa pessoa, o que o leva a ser aprovado, mesmo não sendo o melhor candidato. Essas decisões erradas acarretam custos para a empresa, a partir do momento que impedem que o mais competente faça parte do corpo de funcionários (DESSLER, 2003). 
No contexto dos reality shows, observa-se que dois tipos específicos de jogadores costumam atrair enorme audiência e, por esse mesmo motivo, acabam caindo nas graças dos diretores, que parecem exigir a inclusão de pessoas com tais características em todos os programas: os exibicionistas e os causadores de confusão. Nas organizações, o espetáculo não parece ser muito diferente, ao menos se forem considerados os gestores narcisistas (LUBIT, 2002) e os psicopatas corporativos (KAIHLA e WOOD, 1996), que, não obstante seus comportamentos danosos ao ambiente organizacional, vêm cada vez mais obtendo as vagas e prosperando nas empresas.

Administradores que apresentam padrões de narcisismo destrutivo costumam ter como traços marcantes um sentimento grandioso de sua própria importância, a preocupação exagerada com o poder e com a riqueza, a busca excessiva pela admiração e um menosprezo pelo próximo (LUBIT, 2002). Já os psicopatas corporativos progridem rapidamente em suas carreiras por conta de uma conduta manipuladora e mentirosa, por meio da qual eles se permitem sonhar incessantemente com dinheiro, fama e notoriedade. O psicopata corporativo costuma seduzir e encantar entrevistadores e pessoas que detêm o poder. Uma vez estabelecido na empresa, a falta de sentimento de culpa o leva a mentir e trabalhar pelo seu crescimento na organização: passa a espalhar informações falsas para criar uma imagem ideal e denegrir aqueles que considera seus concorrentes (MAcCOBY, 2000).

Em programas de reality show, pode parecer bastante vantajoso utilizar estereótipos para selecionar jogadores e deles exigir um comportamento forjado e calculado para atingir determinados fins, pois essa é uma boa garantia de que o candidato irá criar situações geradoras de audiência. Nas organizações, entretanto, os efeitos do uso de tais critérios nos protocolos de seleção podem ser danosos às relações de trabalho e ao desempenho da empresa, não só pela eliminação dos candidatos mais adequados como também pela inserção de pessoas que justificam a adoção contumaz de manipulação e representação em função do cumprimento de determinados objetivos.

\section{Os milenares e onipresentes jogos de poder}

Um grupo de indivíduos somente se estabelece em torno de um projeto a cumprir ou de uma ação a executar por meio de um projeto comum, o qual deve estar refletido num "sistema de valores suficientemente interiorizado pelo conjunto dos membros, a fim de conferir ao projeto suas características dinâmicas (fazê-lo passar da etapa do projeto para a realização)" (ENRIQUEZ, 1997, p.92). Esse projeto comum é então compartilhado ou imposto por uma parte às demais por meio das relações estruturais de poder (PAGÉS et al., 1993).

No caso das organizações, todas as formas de ação e intervenção resultam de um processo de controle disciplinar derivado das relações de poder (CLEGG, 1996; PRESTES MOTTA e FREITAS, 2000), as quais perseguem constantemente a legitimação e o consenso, capazes de transformar diferenças em conformidade (ALVES e GALEÃO-SILVA, 2004) e obediência em adesão (PEREIRA e GONDIM, 2002). A construção da realidade social passa necessariamente pelo estudo da noção de poder aplicada aos diferentes contextos (CARVALHO, VIEIRA e LOPES, 1999; FARIA e MENEGHETTI, 2001). Nas empresas, poder e política caminham juntos (FARIA, 2002; MOUSSÉ, 1997; TOWNLEY, 2001); nos reality shows, surgem interessantes jogos políticos capazes de enriquecer a percepção do poder nas instâncias organizacionais.

A disputa por um prêmio leva as pessoas a criarem estratégias - muitas vezes antiéticas - para atingir seus objetivos. Em programas de reality show existe uma recompensa concreta, que é ser declarado o vencedor do jogo e ter direito a receber o prêmio final, geralmente, uma elevada quantia monetária. Há ainda outra recompensa subjetiva: findo o programa, restam a fama e os benefícios dela decorrentes. Em organizações também existem premiações, tais como promoções, remuneração variável pelo desempenho ou a manutenção do emprego; e à recompensa concreta somam-se os prêmios subjetivos de reconhecimento e poder.

Estratégias declaradas e secretas, coalizões, alianças, disputas por poder, manipulação e politicagem fazem parte da essência dos programas de reality show e são estimulados pelos produtores e diretores, pelo efeito causado na audiência. Evidenciando a função pedagógica da cultura de massa (MARCONDES FILHO, 1986), 
o público aprendeu a esperar que os participantes façam tudo que for possível, desconsiderando os limites éticos, para eliminar os outros jogadores e vencer. Já nas empresas, tais procedimentos podem ser extremamente danosos ao desempenho da companhia (KACMAR e FERRIS, 1993; PASKOFF, 2003), mas são praticados diariamente, numa contradição própria do sistema produtor (PAGÈS et al., 1993):

As pessoas na organização passam seu tempo falando a respeito de reinados e construindo-os, controlando impérios, fazendo política empresarial e jogos de poder, promovendo ou descartando alguém da organização, buscando a excelência e tentando ser o número um. Essas palavras são sinônimos da filosofia atual de ser eficiente e eficaz, de buscar a produtividade, ter lucro e ser filantropo (GRIFFIN, 1994, p.24).

A disputa pelo poder decorre da percepção de que é por meio dele que pessoas e grupos podem ser influenciados (CLEGG, 1996; SOTO, 2002; VERGARA, 2000), quer se esteja enfocando as organizações produtivas, quer se esteja discutindo Big Brother ou No Limite. Questões de identidade e representação também estão envolvidas nas disputas de poder, uma vez que "a ação organizacional é o resultado indeterminado de lutas importantes entre diferentes atores, (...) entre pessoas cujas identidades organizacionais serão modeladas pelo modo como as práticas disciplinares pesam sobre elas" (PEREIRA e GONDIM, 2002, p.2).

O quadro 2 lista algumas táticas políticas para se conquistar poder, as quais foram sugeridas para contextos organizacionais; e que podem igualmente ser constatadas nos reality shows.

\section{Quadro 2}

Táticas políticas para conquistar poder

- desenvolver contatos de força - fazer alianças com pessoas poderosas

- administrar sua imagem - apoiar-se no gerenciamento de impressão

- controlar informação vital - mater informação em sigilo até que sirva aos objetivos

- manter-se informado - desenvolver um sistema para ficar a par dos acontecimentos

- melhorar a imagem pessoal - ser cortês, agradável e positivo

- estimular a impressão de competência - fazer com que outras pessoas o elogiem

- evitar erros políticos - nunca criticar pesadamente alguém que poderá favorecê-lo

- elogiar sinceramente - insinuar-se aos outros por meio de elogios honestos

- apunhalar pelas costas - fingir simpatir enquanto se planeja a destruição de alguém

- abraçar ou demolir - eliminar rivais que podem retaliar

- trabalhar pelo erro do outro - criar situações em que os rivais pareçam inábeis

- criar jogos territoriais - acumular recursos que garantem poder e autoridade

Fonte: adaptado de DUBRIN, 2003.

É notório que incontáveis acadêmicos e consultores produziram prescrições semelhantes ao conjunto de táticas mostradas na quadro 2; ao menos desde o final dos anos 1970, quando os estudiosos de estratégia em organizações resolveram resgatar as antigas máximas militares para lidar com as questões de poder (MINTZBERG, AHLSTRAND e LAMPEL, 2000). Entretando, supondo que poucos foram os vencedores de reality shows familiarizados com Sun Tzu e Von Clausewitz, pode-se especular que existem padrões recorrentes nas disputas por poder, os quais parecem tão significativos que são repetidos de forma idêntica, tanto nas competições da televisão quanto nas querelas intra-organizacionais.

Deve ser também observado que no quadro 2 surge, novamente, a questão da representação mobilizada por atores televisivos/organizacionais. Seguindo a diretriz da hiper-realidade, a criação de uma imagem de competência, principalmente, para aqueles que estão acima na hierarquia, torna-se um fator primordial para o 
sucesso do "funcionário ideal": os rótulos passam a preponderar sobre o conteúdo e parecer torna-se mais importante que ser (WOOD Jr. e DE PAULA, 2001). Nesse ponto, passam a ser utilizados discursos que visam supervalorizar a capacidade intelectual e emocional do profissional e manipular os outros com relação à idealização de suas habilidades, criando-se uma figura mítica, forte e capaz da execução de suas tarefas (FARIA e MENEGHETTI, 2001).

Discussões acerca dos jogos de poder envolvem, necessariamente, ponderações sobre estruturas de dominação (CLEGG, 1996), sistemas de comando (PEREIRA e GONDIM, 2002) e, por conseguinte, sobre liderança e indivíduos "loucos pelo poder" (ENRIQUEZ, 1997, p.120). A premência pela ascensão, o predomínio do belicismo nos negócios e a hipertrofia do utilitarismo (CARVALHO e LEITÃO, 2001) conduzem os indivíduos à busca desenfreada pelas posições hierarquicamente privilegiadas na estrutura das organizações. Nesse movimento, como se viu, mais importante do que ser um líder é parecer-se com um.

"Você pode tentar formar a percepção de que é inteligente, com boa aparência, decisivo, de boa verbalização, agressivo, trabalhador e consistente em suas declarações e ações. Isso vai garantir uma liderança de sucesso? Não podemos afirmar que sim. Mas, se você puder projetar apropriadamente essas características, aumentará a probabilidade que seus chefes, colegas e funcionários o vejam como um líder eficaz.” (ROBBINS, 2003, p.63)

Da mesma forma que as pelejas semanais do Big Brother começam pela disputa pelo posto de líder - o qual significa uma posição competitiva privilegiada, que permite a tomada de decisões em nome do grupo e propicia o recebimento de adulações por parte da produção do programa e dos demais jogadores - os profissionais das organizações precisam postar-se em posições de destaque. Assim como no reality show, a liderança na empresa confia, geralmente, na prática do gerenciamento de impressões (CARVALHO e GRISCI, 2002). O uso desse expediente como método de alavancagem da carreira inclui copiar o comportamento vencedor de outros líderes, autopromover-se, agir de forma calculada, planejada e pouco autêntica, além de utilizar os outros como instrumento para auto-realização.

Cabe notar que esse comportamento cria uma nova contradição, em conseqüência das próprias políticas das organizações que, ao estipularem regras de competição interna pouco claras, criam ambigüidade e permitem às pessoas redefinirem as situações de acordo com seus próprios interesses, o que pode gerar sensação de injustiça e desconfiança que abalam o comprometimento de comandantes e comandados (KACMAR e FERRIS, 1993).

Além disso, é comum que as empresas incentivem a competição entre seus funcionários, com o intuito de apenas manter os mais fortes, numa reedição pós-moderna da lei da selva: elas privilegiam o reconhecimento individual em detrimento das realizações coletivas (ROBBINS, 2003). Dessa maneira, um funcionário passa a ver seu colega como o inimigo que deve ser destruído (SUTTON, 2003), a exemplo dos participantes de reality shows, a quem se permite, durante os meses do programa, a construção de laços afetivos de um jogador somente com as pessoas que posteriormente deverão ser eliminadas por ele.

Nesse clima de "vale tudo" - que pode visar tanto à obtenção do prêmio em um reality show quanto à superação de metas em uma empresa - chega-se a registrar discursos de altos executivos em organizações, que consideram que o comportamento dissimulado e prejudicial, bem como sabotagens e fraudes, são pré-requisitos do cargo e que as demandas pela conduta ética não podem ou não devem ser aplicadas a eles (PASKOFF, 2003).

\section{Manipulação do comportamento por um "Grande Irmão"}

A idéia de que somos controlados por forças que estão por trás de nossas decisões e ações é tida como fundamentalmente repugnante para uma racionalidade que se dedicou a construir, ao longo dos séculos, um discurso deliberadamente voltado para negar essa mesma possibilidade (COOPER e BURRELL, 1988). No entanto, entende-se que a sociedade alicerçada pelas organizações emergiu exatamente pelo esforço derivado de um poder capaz de atenuar as paixões humanas, redirecionando-as para o cumprimento de interesses sociais 
e econômicos bem específicos (ENRIQUEZ, 1997, 2001; PAGÈS et al., 1993), geralmente, por meio do senso de pertencimento a um projeto em que o sucesso do indivíduo está relacionado ao modelo de sucesso definido pela organização (BELL e TAYLOR, 2004).

A concepção pós-modernista de "jogo" (COOPER e BURRELL, 1988) aborda a construção da ação social como um jogo de poder no qual os participantes devem realizar determinados movimentos, de acordo com regras reconhecidas por todos e predeterminadas por uma força que tem dominância sobre os jogadores. Ainda que tal noção talvez seja demasiadamente abstrata para os que estão imersos na estrutura organizacional, a discussão de programas como Big Brother pode ser efetiva para propiciar a percepção desse jogo. Nos reality shows, aquelas forças de poder e controle estão claramente incorporadas pelas entidades dos controladores do jogo: autor, diretor e audiência. O modelo comunicacional da indústria cultural é o do videogame, que proporciona aos jogadores/espectadores o prazer de percepções previamente esquematizadas pelo criador do jogo (FREITAS, 2003).

Nos reality shows, os produtores procuram deter o controle das "cenas" que acontecem entre os participantes, com a intenção de gerar situações que atraiam audiência. Para isso, valem-se da tecnologia de câmeras e microfones, da configuração espacial dos cenários, de prêmios intermediários ou benefícios concedidos apenas a alguns participantes, entre outras estratégias, para gerar ciúme, inveja, brigas, paixões, intrigas e muitas outras situações que vão ao encontro de seus objetivos. A capacidade de impor hábitos e a habilidade em ditar comportamentos são características distintivas da cultura de massas (ADORNO, 1990), principalmente, por meio da criação e da manipulação de imagens, as quais, no caso de um reality show, podem ser direcionadas tanto para os jogadores quanto para a platéia.

Contudo, deve ser observado que o "jogo" pós-modernista canaliza as tensões - rancor, inveja, provocação, ciúme (COOPER e BURRELL, 1988; DE VRIES, 1996) - para a potencialização da atividade empresarial, principalmente, por meio da manipulação de sentimentos e interesses individuais (MORGAN, 1996). Nesse contexto, assim como nos reality shows, não se pode abrir mão dos sistemas de vigilância, os quais servem como guardiães das regras de conduta requeridas para o perfeito funcionamento do sistema, mesmo às custas das intermináveis discussões acerca de invasão de privacidade (MATHIJS, 2002; TAYLOR, 2000).

De modo análogo, as organizações também criam mecanismos de controle sobre seus funcionários, para que as metas de desempenho e lucratividade sejam atingidas (FARIA, 2002; PRESTES MOTTA e FREITAS, 2000). Por meio da cultura da empresa, da tecnologia e da arquitetura dos espaços (CLEGG, 1992; DALE e BURRELL, 2002), busca-se impor regras de comportamento (CLEGG, 1996) que tolhem a liberdade dos atores organizacionais.

Quando se trata de discutir manipulação de comportamento, cabe apontar a perspectiva das empresas como "fenômenos culturais" (MORGAN, 1996, p.132), a partir dos quais se define a cultura organizacional como um processo de construção da realidade, utilizado para que as pessoas possam "ver e compreender eventos, objetos, expressões e situações particulares de maneiras distintas". Assim, a cultura organizacional consiste do sistema compartilhado de ações, valores e crenças que se origina numa organização e que ajusta o comportamento das pessoas (ALPANDER e LEE, 1995; TONELLI e ALCADIPANI, 2000). Geralmente, ela determina as ações adequadas e como seus participantes se posicionam no sistema social. Essas regras e papéis culturais constituem parte dos controles normativos da empresa e aparecem nas rotinas diárias (FARIA, 2002; SCHERMERHORN Jr., HUNT e OSBORN, 1999). Nos reality shows, a instauração de uma "cultura" está bem refletida nos itens "impressão de brincadeira", "codificação de ações e falas" e "normatização" do quadro 1. Quando os jogadores passam a repetir jargões vencedores utilizados em outros programas, por exemplo, pode-se creditar esse comportamento ao estabelecimento de um vínculo cultural com os participantes do primeiro programa.

Quando nos recordamos da obra de Orwell (1978), que inspirou os reality shows, percebe-se que a dimensão cultural também tem presença marcante. Vale lembrar a imposição da linguagem que o autor chama de "novilíngua", um processo de redução de palavras que tinha como meta a diminuição do vocabulário para solapar a capacidade crítica das pessoas. Nos programas de reality show, essa lógica parece estar reproduzida 
no largo uso - num primeiro momento, pelos jogadores e, em seguida, obviamente, pelos milhões de fãs do programa - de expressões tais como "tá ligado", "falô", "valeu", "a parada". Ora, quando se estuda a cultura das empresas, com suas siglas particulares desprovidas de significado para muitos daqueles que as repetem GQT, RP, JIT, ISO, RH, P\&D, DP - é possível especular acerca do surgimento de uma estrutura lingüística semelhante.

A cultura da empresa respalda seus valores organizacionais, o que dizer e o que fazer, como diferenciar certo e errado, qual comportamento é valorizado e qual deve ser rejeitado; ou seja, a cultura reflete a "personalidade" da organização (LEWIS, 1996; ROBBINS, 2001). Com esse intuito, criam-se mecanismos como os sistema de premiações (HEWLING, 2003) e a socialização dos novos funcionários (ROBBINS, 2001; 2003). Desta feita, a alta gerência busca incutir em seus empregados valores e representações para que eles ajam da maneira "adequada" e condizente com os objetivos organizacionais, não obstante o alerta de que ao estimular a reprodução acrítica de comportamento e valores, a empresa diminui a diversidade e homogeneiza o pensamento (HEWLING, 2003).

Além da imposição da cultura organizacional, a alta gerência das empresas também utiliza o ambiente de trabalho e a tecnologia como mecanismos de controle e manipulação dos funcionários (VERGARA, CARVALHO e GOMES, 2004). Criam-se espaços esteticamente atraentes, seguros e higiênicos, voltados para a colonização estética e para o controle da subjetividade do trabalhador (DALE e BURRELL, 2002). A utilização instrumental da tecnologia no ambiente de trabalho (CLEGG, 1992) - por intermédio de pontos eletrônicos, circuitos fechados de televisão e fiscalização de mensagens de correio eletrônico - reforçam o domínio do trabalhador pela organização (CLEGG, 1992).

O controle da tecnologia e dos espaços físicos compõe outro pilar fundamental para os shows hiper-reais, mesmo porque esses dois pontos eram cruciais para o "Grande Irmão" do livro de George Orwell (1978). Para construir uma nova realidade, nada melhor do que criar uma nova relação do agente dominador com a dimensão mais frágil e objetiva da vida humana - sua corporeidade (DALE e BURRELL, 2002; SEAMON, 1984).

\section{Considerações finais}

O prazer da experiência proporcionada pela indústria cultural a seus consumidores e demais participantes e espectadores - por meio da idealização e da estilização hiper-real - é o de que a realidade continue exatamente como ela é (FREITAS, 2003). Embora os reality shows atendam perfeitamente a essa demanda do sistema produtor, buscou-se neste ensaio, uma abordagem crítica da cultura de massa, que pode mesmo mobilizar certas potencialidades de negação e/ou emancipação (POGGIOLI, 1963). Dessa perspectiva, a analogia do reality show talvez tenha sua principal contribuição atrelada à possibilidade de que os acadêmicos comuniquem-se com gerentes e outros atores organizacionais por intermédio de uma análise menos estranha aos praticantes, por meio de um prisma analógico que não se preste a oprimi-los ainda mais em função da reprodução, pelo texto erudito, das estruturas hegemônicas de conhecimento e poder (ALVESSON e WILLMOTT, 1996).

Além de invistigar a tangência entre organizações e reality shows - buscando explorar somente três temas comuns, "seleção", "poder" e "manipulação" - o artigo igualmente procurou incentivar o estudo de Big Brother e similares, visando a compreensão do fenômeno organizacional. Aqui, as possibilidades parecem tão numerosas quanto os candidatos a celebridades que concorreram pelas duas vagas disponíveis ao grande público na última edição brasileira do programa.

Por exemplo, o item "vigilância constante" do quadro 1 refere-se a uma das características mais marcantes dos reality shows e típicas das sociedades de controle (DELEUZE, 1992). Considerando que os participantes do programa Big Brother são percebidos como habitantes de um panóptico (ANDREJEVIC, 2002), é possível fazer uma análise crítica da vigilância em reality shows e nas organizações, por meio de analogia fundamentada nas idéias de Michel Foucault (1987), em resposta a recentes demandas de acadêmicos brasileiros (PRESTES MOTTA e ALCADIPANI, 2003). Outra possibilidade de pesquisa diz respeito ao tema da 
"hipercompetitividade" (segundo tópico do quadro 1), que poderia ser estudada pela ótica do gerente como herói principal de um discurso típico do modo de produção capitalista, por meio do qual se celebra a competência interpessoal como recurso competitivo decisivo (RODRIGUES, CARRIERI e LUZ, 1999), precisamente, a mesma habilidade que se demanda dos jogadores de reality shows.

Mesmo os três tópicos abordados neste ensaio parecem longe de estar esgotados pela perspectiva aqui sugerida. Voltando ao quadro 2, é possível remeter para outra instância a questão dos jogos de poder explicitados nos reality shows e nas organizações, pela simples discussão da conduta competitiva dos participantes do Big Brother. É certo que as ciências sociais principiam, elas também, a vigiar os jogadores de reality show, mas é óbvio que esse olhar não se verifica em uma via única. De que outro modo explicar a reprodução de táticas específicas para conquista de poder perfeitamente empregadas pelos jogadores, a menos que se pretenda que eles tenham acesso a compêndios de administração nos cômodos secretos do cenário do programa? Cabe questionar tanto a respeito da relevância do livro-texto para apresentação de conteúdo tido como novo, quanto acerca da descuidada vigilância dirigida pelos acadêmicos de administração ao panóptico que também os circunscreve. 


\section{Referências bibliográficas}

ADORNO, T. Teoria estética. São Paulo: Martins Fontes, 1990.

; HORKHEIM ER, M. Dialética do esclarecimento: fragmentos filosóficos. Rio de Janeiro: Jorge Zahar, 1997.

ALPANDER, G.; LEE, C. Culture, strategy and teamwork: the keys to organizational change. Journal of Management Development, v.14, n.8, p.4-18, Aug. 1995.

ALVES, M.; GALEÃO-SILVA, L. A crítica da gestão da diversidade nas organizações. Revista de Administração de Empresas, v.44, n.3, p.2029, jul./set. 2004.

ALVESSON, M.; DEETZ, S. Teoria crítica e abordagens pós-modernas para estudos organizacionais. In: CLEGG, S.; HARDY, C.; W. NORD, W. (Org.). Handbook de Estudos Organizacionais. São Paulo: Atlas, 1999. v.2, p.227-266.

; WILLM OTT, H. Making sense of management. London: Sage, 1996.

ANDREJEVIC, M. The kinder, gentler gaze of Big Brother. New Media \& Society, v.4, n.2, p.251-270, 2002.

BASTIDE, R. Arte e sociedade. 2.ed. São Paulo: Companhia Editora Nacional/Edusp, 1971.

BAUDRILLARD, J. A transparência do mal: ensaio sobre os fenômenos extremos. Campinas: Papirus, 1990.

BELK, R. Hyperreality and globalization: culture in the age of Ronald McDonald. Journal of International Consumer Marketing, v.8, n.3/4, p.23-37, 1996

BELL, E.; TAYLOR, S. A exaltação do trabalho: o poder pastoral e a ética do trabalho na nova era. Revista de Administração de Empresas, v.44, n.2, p.64-78, abr./jun. 2004

BENAJI, M.; BAZERM AN, M.; CHUGH D. How (un) ethical are you? Harvard Business Review, v.81, n.12, p.56-64, Dec. 2003.

BOJE, D. Resistência carnavalesca ao espetáculo global. Revista de Administração de Empresas, v.42, n.4, out./nov./dez. 2002.

CARR, A. Art as a form of knowledge: the implications for critical management. Tamara - Journal of Critical Postmodern Organization Science, v.2, n.1, p.8-30, 2002.

CARVALHO, C.; VIEIRA, M.; LOPES, F. Contribuições da perspectiva institucional para análise das organizações. In: ENCONTRO DA ASSOCIAÇÃO NACIONAL DOS PROGRAM AS DE PÓS-GRADUAÇÃO EM ADMINISTRAÇÃ̃O, 23., 1999, Foz do Iguaçu. Anais... Foz do Iguaçu: Anpad, 1999.

CARVALHO, J.; LEITÃO, S. Violência e mudança nas organizações: uma crítica à metáfora "Business-as-War". Revista de Administração Pública, v.35, n.2, p.39-61, mar./abr. 2001.

CARVALHO, M.; GRISCI, C. Gerenciamento de impressão em entrevistas de seleção: camaleões em cena. In: ASSEMBLÉlA DO CONSELHO LATINO-AMERICANO DE ESCOLAS DE ADM INISTRAÇÃO, 37., 2002, Porto Alegre. Anais... Porto Alegre: Cladea, 2002.

CASE, T. Segredos de uma dinâmica de grupo. Jornal Carreira \& Sucesso, n.212, 15 jan. 2004. Disponível em: $<$ http://www.catho.com.br/jcs/inputer_view.phtml?id=6461>.

CHIARI, T. Como estar na mira das empresas. Veja Sua Carreira, n.1, p.16-21, 2000.

CLEGG, S. Tecnologia, instrumentalidade e poder nas organizações. Revista de Administração de Empresas, v.32, n.5, p.68-95, nov./dez. 1992.

Poder, linguagem e ação nas organizações. In: CHANLAT, J. 0 indivíduo na organização: dimensões esquecidas. 3.ed. São Paulo: Attlas, 1996. v.1, p.47-66.

COOPER, R.; BURRELL, G. Modernism, postmodernism and organizational analysis: an introduction. Organization Studies, v.9, n.1, p.91$112,1988$.

CORREIA, J. Os administradores de ilusões: espectáculo, subjetividade e ideologia na cultura mediática contemporânea. Media \& Jornalismo, n.2, mar. 2003.

DALE, K.; BURRELL, G. An-aesthetics and architecture. Tamara - Journal of Critical Postmodern Organization Science, v.2, n.1, p.77-90, 2002.

DE VRIES, M. A inveja, grande esquecida dos fatores motivadores em gestão. In: CHANLAT, J. 0 indivíduo na organização: dimensões esquecidas. 3.ed. São Paulo: Atlas, 1996. v.1, p.67-82.

DEBORD, G. The society of spectacle. New York: Zone Books, 1995.

DELEUZE, G. Conversações. São Paulo: Editora 34, 1992.

DESSLER, G. Administração de recursos humanos. 2.ed. São Paulo: Prentice Hall, 2003. 
DUBRIN, A. Fundamentos do comportamento organizacional. São Paulo: Pioneira Thomson Learning, 2003.

ENRIQUEZ, E. A organização em análise. Petrópolis: Vozes, 1997.

. Interioridade e organizações. In: DAVEL, E.; VERGARA, S. Gestão com pessoas e subjetividade. São Paulo: Atlas, 2001. p.173-187.

FARIA, J. Economia política do poder: uma proposta teórico- metodológica para o estudo e a análise das organizações. In: ENCONTRO DE ESTUDOS ORGANIZACIONAIS, 2., 2002, Recife. Anais... Recife: Anpad, 2002.

; MENEGHETTI, F. Discursos organizacionais. In: ENCONTRO DA ASSOCIAÇÃO NACIONAL DOS PROGRAMAS DE PÓS-GRADUAÇÃO EM ADMINISTRAÇÃO, 25., 2001, Campinas. Anais... Campinas: Anpad, 2001.

FISCHER, E. A função da arte. In: VELHO, G. (Org.). Sociologia da arte, Rio de Janeiro: Zahar, 1966. p.15-23. (Textos Básicos de Ciência Social, tomo I).

FOUCAULT, M. Vigiar e punir. Petrópolis: Vozes, 1987.

FREITAS, V. Adorno e a arte contemporânea. Rio de Janeiro: Jorge Zahar, 2003.

FRÉMION, Y. Um anúncio vale mil bombas. In: PERRAULT, G. (Org.). 0 livro negro do capitalismo. 3.ed. Rio de Janeiro: Record, 2000, p.515-529.

FRIDMAN, L. Vertigens pós- modernas. Rio de Janeiro: Relume Dumará, 2000.

GALVÃO, C. Maratona do emprego. Veja Sua Carreira, n.1, p.36-40, 2000.

GRIFFIN, G. Maquiavel na administração: como jogar e ganhar o jogo do poder na empresa. São Paulo: Atlas, 1994.

GUERREIRO RAM OS, A. Patologia social do "branco" brasileiro. In: Introdução crítica à sociologia brasileira. Rio de Janeiro: Editora UFRJ, 1995.

HANCOCK, P. Aestheticizing the world of organization: creating beautiful untrue things. Tamara - Journal of Critical Postmodern Organization Science, v.2, n.1, p.91- 105, 2002.

HAUSER, A. A era do filme. In: VELHO, G. (Org.). Sociologia da arte, Rio de Janeiro: Zahar, 1966. p.37- 70. (Textos Básicos de Ciência Social, tomo I).

HEWLING, P. And the award for best actor goes to...: facades of conformity in organizational settings. Academy of Management Review, v.28, n.4, p.633-642, Oct. 2003.

HOLBROOK, M. The millennial consumer in the texts of our times - part 3: exhibitionism. Journal of Macromarketing, v.21, n.1, p.81-95, June. 2001.

INGHAM, B. The meaning of development: interactions between "new" and "old" ideas. World Development, v.21, n.11, p.1803-1821, 1993.

JONES, J. Show your real face. New Media \& Society, v 5, n.3, p.400-421, 2003.

KACM AR, L.; FERRIS, G. Politics at work: sharpening the focus of political behavior in organizations. Business Horizons, v.36, n.4, p.70- 74, July/Aug. 1993.

KAIHLA, P.; WOOD, C. No conscience, no remorse. Maclean's, v.109, n.4, p.50-51, 22 Jan. 1996.

KOZINETS, R. Can consumers escape the market? Emancipatory illuminations from burning man. Journal of Consumer Research v.29, p.20-38, Sept. 2002

LEWIS, D. The organizational culture saga - from OD to TQM : a critical review of the literature. Leadership \& Organization Development Journal, v.17, n.1, p.12-19, Jan. 1996.

LUBIT, R. 0 impacto dos gestores narcisistas nas organizações. Revista de Administração de Empresas, v.42, n.3, p.66-77, jul./set. 2002.

LUKÁCS, G. História e consciência de classe: estudos de dialética marxista. 2.ed. Rio de Janeiro: Elfos, 1989.

MAcCOBY, M. Why should the best talent work for you? Research Technology Management, v.43, n.5, p.57-58, Sept./Oct. 2000.

MARCONDES FILHO, C. Quem manipula quem: poder e massas na indústria da cultura e da comunicação no Brasil. Petrópolis: Vozes, 1986.

MATHIJS, E. Big Brother and critical discourse. Television \& New Media, v.3, n.3, p.311-322, Aug. 2002.

M CALISTER, M. Liquidação de metáforas. In: ENCONTRO DA ASSOCIAÇÃO NACIONAL DOS PROGRAMAS DE PÓS-GRADUAÇÃO EM ADMINISTRAÇÃO, 22., 1998, Foz do Iguaçu. Anais... Foz do Iguaçu: Anpad, 1998.

MENDONÇA, J.; GONÇALVES, J. Responsabilidade Social nas Empresas: uma questão de imagem ou de substância. In: ENCONTRO DA ASSOCIAÇÃO NACIONAL DOS PROGRAM AS DE PÓS- GRADUAÇÃO EM ADMINISTRAÇÃO, 26., 2002, Salvador. Anais... Salvador: Anpad, 2002. 
MINTZBERG, H.; AHLSTRAND, B.; LAMPEL, J. Safári de estratégia: um roteiro pela selva do planejamento estratégico. Porto Alegre: Bookman, 2000.

MIXON J r., F. Cartel (in)stability on survivor island. Journal of Education for Business, v.77, n.2, p.89- 95, Nov./Dec. 2001.

MORGAN, G. Imagens da organização. São Paulo: Atlas, 1996.

MOUSSÉ, J. Ethique et profit aujourd hui. Revue Française de Gestion, p. 52-58, jan./fév. 1997.

MURPHY, K. A twist in survival tales ensures ongoing drama. The Australian, p. B12, 11 Dec. 2003.

NOGUEIRA, D. Deu a louca no RH. Jornal do Brasil, 7 abr. 2002. Revista Domingo, p.24.

ORWELL, G. 1984. 11.ed. São Paulo: Companhia Editora Nacional, 1978.

PAGÈS, M. et al. 0 poder das organizações. 2.ed. São Paulo: Atlas, 1993.

PALLOTTINI, R. Dramaturgia de televisão. São Paulo: Moderna, 1998.

PASKOFF, S. Teaching big shots to behave. Workforce Management, v.82, n.10, p.16-17, Oct. 2003.

PELZER, P. "Dead man": um encontro com o passado desconhecido. Revista de Administração de Empresas, v.42, n.4, p.36-46, out./dez. 2002.

PEREIRA, F.; GONDIM, A. 0 conflito de poder nas organizações: uma evidência empírica. In: ASSEMBLÉIA DO CONSELHO LATINOAMERICANO DE ESCOLAS DE ADMINISTRAÇÃO, 37., 2002, Porto Alegre. Anais... Porto Alegre: Cladea, 2002.

PERELM AN, C.; OLBRECHTS-TYTECA, L. Tratado da argumentação: a nova retórica. São Paulo: Martins Fontes, 1996.

PINHEIRO, P. Aristóteles e o teatro: mímesis, kátharsys e mýthos. 0 Percevejo - Teatro Contemporâneo e Narrativas, Rio de Janeiro: UniRio, n.9, 2000.

POGGIOLI, R. Arte de vanguarda e alienação. Cadernos Brasileiros, n.2, p.3-14, mar./abr. 1963.

PRESTES MOTTA, F.; ALCADIPANI, R. 0 pensamento de Michel Foucault na teoria das organizações. In: ENCONTRO DA ASSOCIAÇÃO NACIONAL DOS PROGRAMAS DE PÓS- GRADUAÇÃO EM ADM INISTRAÇÃO, 27., 2003, Atibaia. Anais... Atibaia: Anpad, 2003.

; FREITAS, M. (Org.). Vida psíquica e organização. São Paulo: Editora FGV, 2000.

ROBBINS, S. Organizational behavior. 9.ed. Upper Saddle River: Prentice Hall, 2001.

A verdade sobre gerenciar pessoas: ... e nada mais que a verdade. São Paulo: Pearson Education, 2003.

RODRIGUES, S.; CARRIERI, A.; LUZ, T. Competição organizacional: bricolagem simbólica e seus significados para os gerentes. In: ENCONTRO DA ASSOCIAÇÃO NACIONAL DOS PROGRAMAS DE PÓS-GRADUAÇÃO EM ADMINISTRAÇÃO, 23., 1999, Foz do Iguaçu. Anais... Foz do Iguaçu: Anpad, 1999.

SANTOS, J. A geração "U- hu!". 0 Globo, 12 jan. 2004. Segundo Caderno, p.8.

SARSUR, A.; SILVA, R. Empregabilidade estratégica: como as organizações transformam guerreiros vencedores em sujeitos fragmentados. In: ASSEM BLÉIA DO CONSELHO LATINO-AMERICANO DE ESCOLAS DE ADM INISTRAÇÃO, 37., 2002, Porto Alegre. Anais... Porto Alegre: Cladea, 2002.

SCANNELL, P. Big Brother as a television event. Television \& New Media, v.3, n.3, p.271-282, Aug. 2002.

SCHERMERHORN J r., J.; HUNT, J.; OSBORN, R. Fundamentos de comportamento organizacional. 2.ed. Porto Alegre: Bookman, 1999.

SEAMON, D. Phenomenologies of environment and place. Phenomenology + Pedagogy, v.2, n.2, p.130-135, 1984.

SILVA, A. Proposta de um perfil de administrador para a era da informação e do conhecimento. In: ENCONTRO DA ASSOCIAÇÃO NACIONAL DOS PROGRAMAS DE PÓS- GRADUAÇÃO EM ADM INISTRAÇÃO, 24., 2000, Florianópolis. Anais... Florianópolis: Anpad, 2000.

SM ITH, R. The catastrophe of paradox: questions and answers on hyperreal America with Jean Baudrillard. Space $\&$ Culture, v.5, n.2, p.96102, May 2002.

SOTO, E. Comportamento organizacional: o impacto das emoções. São Paulo: Pioneira Thomson Learning, 2002.

SUTTON, R. The enemy next door. CIO Insight, n.33, p.35-36, Nov. 2003.

TAVARES, F. Mitologização midiática: os mitos emergentes da televisão. Comum, v.5, n.14, p.33-52, jan./jul. 2000.

TAYLOR, J. Big business as Big Brother: is employee privacy necessary for a human-centered management organization? Business \& Professional Ethics Journal, v.19, n.3/4, p.13-29, 2000.

TELEVISÃO dedicada ao estilo "Big Brother". 0 Globo, Rio de Janeiro, 15 jul. 2004. p.30. 
TINCKNELL, E.; RAGHURAM , P. Big Brother: reconfiguring the "active" audience of cultural studies? European Journal of Cultural Studies, V.5, n.2, p.199-215, 2002.

TONELLI, M.; ALCADIPANI, R. Organizações pós- modernas: uma discussão sobre as novas competências requeridas aos gestores e a maquiagem do self. In: ENCONTRO DA ASSOCIAÇÃO DOS PROGRAMAS DE PÓS- GRADUAÇÃO EM ADMINISTRAÇÃO, 24., 2000, Florianópolis. Anais... Florianópolis: Anpad, 2000.

TOWNLEY, B. Conhecimento e poder nas organizações. In: DAVEL, E.; VERGARA, S. Gestão com pessoas e subjetividade. São Paulo: Atlas, 2001. p.117-148.

VAN DONGEN, R. Colombians want real life to mimic reality TV. The Christian Science Monitor, p.1-2, Oct. 14, 2003.

VERGARA, S. Gestão de pessoas. São Paulo: Atlas, 2000.

; CARVALHO, J.; GOMES, A. Controle e coerção: a pedagogia do olhar na espacialidade do teatro e das organizações. Revista de Administração de Empresas, v.44, n.3, p.10-19, jul./set. 2004.

WEICK, K. A Estética da imperfeição em orquestras e organizações. Revista de Administração de Empresas, v.42, n.3, p.6-18, jul./set. 2002.

WEINBERG, M.; BRASIL, S. 0 segundo vestibular. Veja, ano 35, n.50, p.168-177, 17 dez. 2003.

WOOD J r., T. M etáforas espetaculares: do dramatismo teatral ao dramatismo cinematográfico. In: ENCONTRO DA ASSOCIAÇÃO NACIONAL DOS PROGRAMAS DE PÓS-GRADUAÇÃO EM ADM INISTRAÇÃO, 24., 2000, Florianópolis. Anais... Florianópolis: Anpad, 2000.

; DE PAULA, A. Pop-management. In: ENCONTRO DA ASSOCIAÇÃO NACIONAL DOS PROGRAMAS DE PÓS-GRADUAÇÃO EM ADMIINISTRAÇÃO, 25., 2001, Campinas. Anais... Campinas: Anpad, 2001.

XEXÉO, A. Gecilda, a musa improvável do "BBB". 0 Globo, 21 jan. 2004. Segundo Caderno, p.8.

ZARIFIAN, P. Comunicação e subjetividade nas organizações. In: DAVEL, E.; VERGARA, S. Gestão com pessoas e subjetividade. São Paulo: Atlas, 2001. p.151-170. 